\title{
Monitored conditions in wooden wall plates in relation to mold and wood decaying fungi
}

\author{
Tessa Kvist Hansen ${ }^{1 *}$, Nickolaj Feldt Jensen ${ }^{2}$, Eva Møller $^{2}$, Ernst Jan de Place Hansen ${ }^{1}$, and Ruut Peuhkuri ${ }^{1}$ \\ ${ }^{1}$ Aalborg University, Department of the Built Environment, 2450 Copenhagen, Denmark \\ ${ }^{2}$ Technical University of Denmark, Department of Civil Engineering, 2800 Kgs. Lyngby, Denmark
}

\begin{abstract}
In historic masonry buildings, wood can be embedded in the walls as storey partition beams, or as supportive wall plates. Half-timbered masonry constructions, or wooden frames, e.g. combined with internal insulation, are other examples of wooden elements. Wood decaying fungi can cause serious damage to wood, which may lose mass and strength, ultimately yielding the risk of collapse. In addition, some fungal species may even be hazardous for occupants. All wood decaying fungi depend on favorable moisture and temperature conditions, although the threshold conditions may vary with various fungal species and types, and state of the wood. To predict the risk of occurrence of wood rot, several models have been developed, however most of these are based on a limited number of experiments, or very specific cases. For these reasons, the applicability of the models to other scenarios (fungal species, wood species) may not be appropriate. Furthermore, another failure mode for wood and moisture, is mold growth, which is initiated at lower moisture levels. An indication of risk of mold growth would indicate problems or risks before the initiation of wood rot. Mold growth does not deteriorate the wood, but is usually equally undesired due to health concerns of occupants. For this reason, there might be places where some mold growth would be acceptable, e.g. embedded beam ends if there is no transfer of air from the moldy area to the indoor air. Therefore, risk of rot could be important. The paper investigates models for mass loss due to wood decay and mold growth based on exposure time to favorable hygrothermal conditions. The investigation is based on inspection of wood samples (wall plates) from a fullscale experimental setup of masonry with embedded wood and monitored conditions, to which the prediction models will be applied. Monitored hygrothermal conditions were implemented in mold and wood decay models, and samples were removed from the test setup. The implemented models yielded high mold index and mass loss, whereas neither mold nor decay was observed in the physical samples. Results indicate that the implemented models, in these cases appear to overestimate the risks of mold and rot in the supportive lath behind the insulation.
\end{abstract}

\section{Introduction}

In older masonry buildings, wood is often embedded in the walls as storey partitioning beams, supportive wall plates, or wooden frames in half-timbered masonry. Thus, the wooden elements can be significant load-bearing elements. Wood decaying fungi usually causes wood to lose strength, and change shape and color. A reduced strength and mass due to fungal attack can therefore have substantial consequences. Furthermore, the fungi may release unpleasant odors, and inhalation of airborne microorganisms and metabolites of some species may cause symptoms of respiratory problems for building occupants, depending on exposure and immunological reactivity [1]. Biological degradation of wood is a naturally occurring process of fungal growth given favorable conditions of both e.g., moisture and temperature. Most wood decaying fungi have optimum conditions at $20-30^{\circ} \mathrm{C}$, and a wood moisture content of 20 $30 \%$ (wt.). Wood-decaying fungi colonize in wood with a moisture content above $20 \%$ (wt.) [1], and below $70 \%$ (wt.) [2]. Some species are able to decay wood at lower moisture levels than $20 \%$ (wt.) and still other species prefer much higher moisture contents for optimal growth. There are more than 30 known wood decaying fungi species as may be found in buildings [3], and they have different preferences and optimal growth conditions. Some species can hibernate in dry periods, and the decay will once again initiate when moisture conditions allow it [4]. Some decay processes are very slow, and actual mass and strength loss can take years to develop [3]. Other fungi can cause serious damage within short time frames given optimal conditions. The optimal moisture conditions for fungal growth also depends on other factors, such as the time of wetness, temperature and the type and condition of the wood. Previously attacked wood is also more prone to new attacks.

There are three types of rot fungi that initiate wood decay; brown rot, soft rot and white rot [5]. Brown rot is initiated earlier and develops faster when compared to the other types. Furthermore, brown rot causes higher mass and strength loss when compared to white and soft rot on southern pine sapwood [6]. The more aggressive behavior of brown rot has also been demonstrated by Brischke et al. especially in sap and non-colored heartwood of European larch, Douglas fir, scots pine and Norway spruce [7]. They also found, that some species, e.g. larch and pine, were more sensitive to decay fungi when compared to fir.

\footnotetext{
${ }^{*}$ Corresponding author: tessa@build.aau.dk
} 
Models for prediction of wood decay have been developed to evaluate the risk of decay under given conditions in structures. Similarly, models have been developed for prediction of the risk of mold growth under dynamic temperature and relative humidity conditions, and for different material sensitivity classes.

In this paper, indicative experimental investigations and dynamic models for mass loss due to wood decay and mold growth based on exposure time to favorable hygrothermal conditions for the formation of wood rot are compared. The investigation is based on inspection of wood samples (wall plates) from a full-scale experimental setup of masonry with embedded wood and monitored hygrothermal conditions, to which the prediction models will be applied.

The paper first describes the two applied wood decay models and one mold model. Thereafter, the experimental setup is described, as well as the method for removal of wooden samples and measurements performed. The monitored conditions in the wall plates that were investigated are presented and discussed, as well as results using prediction models, monitored moisture content and observed decay and mold growth.

\section{Methods}

Both prediction models and experimental methods have been implemented in this study for comparison of the predicted and observed conditions of the wood. In-situ measurements of hygrothermal conditions in wall plates were implemented in prediction models for mold and decay, and using a destructive method, wood samples were removed from the test setup and studied with regard to the predicted risks.

\subsection{Prediction models}

For evaluation of the risks of wood decay or mold growth, models for the prediction of risks have been implemented. The models are briefly described in the next sections.

\subsubsection{VTT wood decay model}

The VTT wood decay model accounts for the period of time in which the hygrothermal conditions (temperature, $\mathrm{T}$, and relative humidity, $\mathrm{RH}$ ) are favorable with regard to wood decay [5]. The model generates a percentage of irreversible mass loss, ML [\%], in the wood. The original model, described in equation 1 , was developed for brown rot decay in sapwood under constant conditions with $\mathrm{T} \geq 0{ }^{\circ} \mathrm{C}$ and $\mathrm{RH} \geq 95 \%$. Under dynamic hygrothermal conditions, the mass loss is separated in two processes; the activation process and a mass loss process. The activation process is defined by $\alpha$ (equation 2-4) which is initially 0 . When $\alpha$ reaches 1 , the decay process is initiated and the mass loss is described in Equation 5;

$$
\begin{gathered}
M L(R H, T, t)=-42.9 t-2.3 T-0.035 R H+ \\
0.14 T \cdot t+0.024 T \cdot R H+0.45 R H \cdot t[\%] \\
\alpha(t)=\int_{0}^{t} d \alpha=\sum_{0}^{t}(\Delta \alpha)
\end{gathered}
$$

$$
\begin{gathered}
\Delta \alpha=\left\{\begin{array}{c}
\frac{\Delta t}{t_{\text {crit }}(R H, T)}, \text { if } T>0{ }^{\circ} C \text { and } R H>95 \% \\
\frac{\Delta t}{17520}, \text { otherwise }
\end{array}\right. \\
t_{\text {crit }}(R H, T)=\left(\frac{2.3 T+0.035 R H-0.024 T \cdot R H}{-42.9+0.14 T+0.45 R H}\right)[h] \\
\frac{M L(R H, T)}{d t}=-5.96 \cdot 10^{-2}+ \\
1.96 \cdot 10^{-4} T+6.25 \cdot 10^{-4} R H[\% / h]
\end{gathered}
$$

\subsubsection{Japanese wood decay model}

Similarly to the VTT model, the Japanese model defines mass loss due to wood decay, based on hygrothermal conditions ( $T, R H)$, and exposure time $[8,9]$. The development of the Japanese wood decay model was based on rate constants determined by mass loss in small wood samples (Japanese red pine) with brown rot fungus. In this model, mass loss initiates when the relative humidity exceeds $98 \%$, which is defined as the critical relative humidity, $\mathrm{RH}_{\text {crit }}$, as no mass loss was observed at lower relative humidities. The Japanese model neglects the initial response time for delay, when conditions reach $\mathrm{RH}_{\text {crit. }}$ The mass loss due to wood decay is generated through equations $6-8$, and output of the model is mass loss in $\mathrm{kg} / \mathrm{kg}$. The mass loss at surface points is found by equation 6, whilst the mass loss at inner points in a construction is defined by equation 7 . The rate constant for mass loss, $k_{m}[1 / s]$, is found by equation 8 .

$$
\begin{gathered}
\left.\frac{d L}{d t}\right|_{x=0}=k_{m}(T) \quad\left(R H_{i} \geq R H_{\text {crit }}\right)\left[\frac{\mathrm{kg}}{\mathrm{kg}}\right] \\
\left.\frac{d L}{d t}\right|_{x>0}=k_{m}(T) \quad\left(L_{i-1} \text { or } L_{i+1}>0, R H_{i} \geq R H_{\text {crit }}\right)\left[\frac{\mathrm{kg}}{\mathrm{kg}}\right] \\
k_{m}(T)=\left(2.77-3.23 T+0.865 T^{2}-0.0189 T^{2}\right) \cdot 10^{-10}
\end{gathered}
$$

\subsubsection{VTT Mold model}

\begin{tabular}{|c|c|}
\hline $\mathbf{M}$ & Description of growth rate \\
\hline 0 & No growth, spores not activated \\
\hline 1 & $\begin{array}{l}\text { Small amounts of mold on surface (microscope), initial stages } \\
\text { of local growth }\end{array}$ \\
\hline 2 & Several local mold growth colonies on surface (microscope) \\
\hline 3 & $\begin{array}{l}\text { Visual findings of mold on surface, }<10 \% \text { coverage, or, } \\
<50 \% \text { coverage of mold (microscope) }\end{array}$ \\
\hline 4 & $\begin{array}{l}\text { Visual findings of mold on surface, } 10-50 \% \text { coverage, or, } \\
>50 \% \text { coverage of mold (microscope) }\end{array}$ \\
\hline 5 & Plenty of growth on surface, $>50 \%$ coverage (visual) \\
\hline 6 & Very heavy and tight growth, coverage around $100 \%$ \\
\hline
\end{tabular}

The VTT mold model generates a mold index, M [-], based on given boundary conditions of temperature and relative humidity, as well as considering the sensitivity class of the substrate. The mold index, $\mathrm{M}$, is a number between 0 and 6 indicating the amount of mold growth to be expected under given conditions on the given substrate. The definitions of the various values for mold index are given in Table 1.

Table 1. Mold growth index classification [10] 
The model index is found by means of equation 9 below [10,11]. In this case, SQ (surface quality) was 0 for sawn surfaces, and $\mathrm{W}$ (wood species) was 0 for pine. The factors $\mathrm{k}_{1}$ and $\mathrm{k}_{2}$ are correction coefficients for mold growth intensity and moderation of mold growth intensity as $\mathrm{M}$ approaches $\mathrm{M}_{\max }$. The value of $\mathrm{M}_{\max }$ is the maximum mold index value achieved under the given conditions, and constant factors $\mathrm{A}, \mathrm{B}$ and $\mathrm{C}$ are determined by $\mathrm{k}_{2}$ and the sensitivity class [10].

$$
\begin{gathered}
\frac{d M}{d t}=\frac{1}{7 \cdot e^{-0.68 \ln (T)-13.9 \ln (R H)+0.14 W-0.33 S Q+66.02}} \cdot k_{1} k_{2} \\
k_{1}=\left\{\begin{array}{c}
\frac{t_{M=1, \text { pine }}}{t_{M=1}}, M<1 \\
2 \cdot \frac{t_{M=3, \text { pine }}-t_{M=1, \text { pine }}}{t_{M=3}-t_{M=1}}, M>1
\end{array}\right. \\
k_{2}=\max \left\{\begin{array}{r}
1-e^{2.3 \cdot\left(M-M_{\text {max }}\right)} \\
0
\end{array}\right. \\
M_{\text {max }}=A+B \cdot \frac{R H_{\text {crit }}-R H}{R H_{\text {crit }}-100}-C \cdot\left(\frac{R H_{\text {crit }}-R H}{R H_{\text {crit }}-100}\right)^{2}
\end{gathered}
$$

To take into account the decline of mold growth during unfavorable conditions, the extent of degradation of mold must also be considered. The reduction in value of mold index is defined as presented in equations 13 (mold decline intensity for pine) and 14 (mold decline intensity for any material given the recurrence coefficient $\mathrm{C}_{\text {mat }}$ ). For this work, the material is classified as "sensitive", corresponding to planed wood, paper-based products, and wood-based panels (e.g. planed pine, glulam). The recurrence coefficient $\mathrm{C}_{\mathrm{mat}}$, was set to 1 , corresponding to untreated wood or pine.

$$
\begin{gathered}
\left(\frac{d M}{d t}\right)_{0}=\left\{\begin{array}{c}
-0.00133, \text { when } t-t_{1} \leq 6 h \\
0, \text { when } 6 h \leq t-t_{1} \leq 24 h \\
0.000667, \text { when } t-t_{1}>24 h
\end{array}\right. \\
\frac{d M}{d t_{\text {mat }}}=C_{\text {mat }} \cdot\left(\frac{d M}{d t}\right)_{0}
\end{gathered}
$$

\subsection{Experimental investigations}

\subsubsection{Large scale experimental setup}

A large-scale experimental setup at the Technical University of Denmark consisted of 24 internally insulated solid masonry wall sections with embedded wooden beams and supportive wall plates (pine). A section view of the wall configurations is given in Fig. 1; red dots and numbers represent monitoring points for temperature and relative humidity (digital HYT 221 sensors; $\left.\pm 1.8 \% \mathrm{RH}\left(23^{\circ} \mathrm{C}, 0-90 \% \mathrm{RH}\right)\right)$. The experimental setup was first and foremost conducted for evaluating the performance of several different internal insulation systems, which have been further described, analyzed and reported in [12-14]. For the present study, samples from the wooden supportive wall plate were taken from six of these walls. By means of sorption isotherms for pine [15], the moisture content was determined. In this study, only results from measuring point no. 5 , in the wall plate, have been included.

Four years of measurement data (5/1/2015-5/1/2019) from sensor location 5 (supportive wall plate) were studied, and the cases with highest relative humidity were implemented in the VTT wood decay model. Six walls showed very high wood decay according to the VTT model, and were chosen for further investigation. All of these walls were oriented towards the SW, and the wall configurations are elaborated in Table 2 with regard to insulation system, and internal and external surface treatments. The digital RH measurements for the wooden wall plates were used for both the wood decay models as well as the mold model.

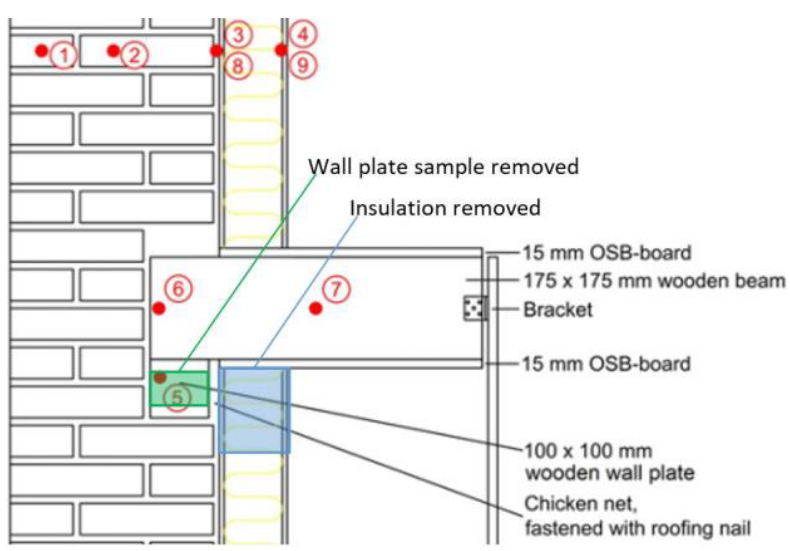

Fig. 1. Section view of the walls from the experimental setup,

\begin{tabular}{|c|c|c|c|c|}
\hline & $\begin{array}{l}\text { Interior } \\
\text { insulation } \\
\text { system, } \\
100 \mathrm{~mm}\end{array}$ & $\begin{array}{l}\text { Exterior } \\
\text { surface }\end{array}$ & $\begin{array}{l}\text { Interior } \\
\text { surface }\end{array}$ & $\begin{array}{l}\text { Thermal } \\
\text { resistance } \\
{\left[\mathbf{m}^{2} \mathbf{K} / \mathbf{W}\right]}\end{array}$ \\
\hline G1 & $\begin{array}{l}\text { Mineral wool + } \\
\text { vapor barrier }\end{array}$ & $\begin{array}{l}\text { Bare } \\
\text { brick }\end{array}$ & $\begin{array}{l}\text { Gypsum + } \\
\text { Acrylic } \\
\text { paint }\end{array}$ & 3.16 \\
\hline G4 & $\begin{array}{l}\text { Calcium } \\
\text { silicate }\end{array}$ & $\begin{array}{l}\text { Bare } \\
\text { brick }\end{array}$ & $\begin{array}{l}\text { Diffusion } \\
\text { open paint }\end{array}$ & 2.26 \\
\hline G5 & Foam concrete & $\begin{array}{l}\text { Bare } \\
\text { brick }\end{array}$ & $\begin{array}{l}\text { Diffusion } \\
\text { open paint }\end{array}$ & 2.27 \\
\hline X1 & $\begin{array}{l}\text { Autoclaved } \\
\text { aerated } \\
\text { concrete }\end{array}$ & Render & $\begin{array}{l}\text { Diffusion } \\
\text { open paint }\end{array}$ & 3.00 \\
\hline $\mathbf{X} 2$ & $\begin{array}{l}\text { Autoclaved } \\
\text { aerated } \\
\text { concrete }\end{array}$ & $\begin{array}{l}\text { Bare } \\
\text { brick }\end{array}$ & $\begin{array}{l}\text { Diffusion } \\
\text { open paint }\end{array}$ & 2.98 \\
\hline X8 & $\begin{array}{l}\text { Autoclaved } \\
\text { aerated } \\
\text { concrete }\end{array}$ & $\begin{array}{l}\text { Bare } \\
\text { brick }\end{array}$ & $\begin{array}{l}\text { Acrylic } \\
\text { paint }\end{array}$ & 2.98 \\
\hline
\end{tabular}
and indication of measurement points in the construction

Table 2. Descriptions of walls from which the supportive wall plate was investigated with regard to wood decay and mold growth, and estimated values of thermal resistance through the construction*

${ }^{*}$ Estimations based on: $348 \mathrm{~mm}$ brick, $\lambda_{\text {brick }}=0.6 \mathrm{~W} / \mathrm{mK}, 10 \mathrm{~mm}$ internal and external render, $\lambda_{\text {render }}=0.5 \mathrm{~W} / \mathrm{mK}, 100 \mathrm{~mm}$ of each insulation with $\lambda_{\text {min.wool }}=0.04 \mathrm{~W} / \mathrm{mK}, \lambda_{\text {CaSi }}=0.061 \mathrm{~W} / \mathrm{mK}, \lambda_{\text {foam concrete }}$ $=0.064 \mathrm{~W} / \mathrm{mK}, \lambda_{A A C}=0.044 \mathrm{~W} / \mathrm{mK}$. $10 \mathrm{~mm}$ adhesive, $8 \mathrm{~mm}$ int. render for $\mathrm{CaSi}, \lambda_{\text {ad.ren } \mathrm{CaSi}}=0.5 \mathrm{~W} / \mathrm{mK}, 8 \mathrm{~mm}$ adhesive and render for $A A C$ and foam concrete, $\Lambda_{\text {ad.ren.foam } . A A C}=0.155 \mathrm{~W} / \mathrm{mK}$

\subsubsection{Destructive investigation}

To study the conditions of the wall plates, and indications of rot and mold, Ø80mm samples were extracted by cupdrilling the construction from the inside after removal of the covering insulation and finishing. The samples were visually inspected and smelt for any odors to permit detecting signs of either rot or mold; the material resistance towards awl compression was also assessed. 
A rule of thumb says, that if the awl penetrates $1-3 \mathrm{~mm}$, the wood is healthy. A $3-6 \mathrm{~mm}$ penetration indicates that the wood is very moist, and possibly attacked by wood rot. If the penetration depth of the awl exceeds $6 \mathrm{~mm}$, there is likely a comprehensive fungi attack [16].

The moisture content of the wood was measured with a pin gauge on the internal surface immediately after removal of covering insulation, and on the external surface after the sample was removed from the construction. Furthermore, the mass of each sample was registered directly after removal from the wall that thereafter, allowed determining the total moisture content in the sample. This was performed by weigh-dry-weigh method, where the specimens were dried at $105^{\circ} \mathrm{C}$ until constant mass. a)

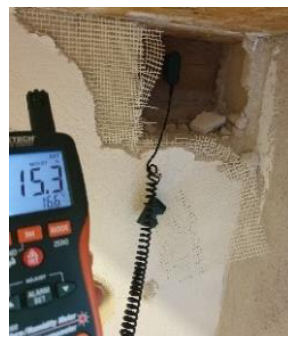

c)

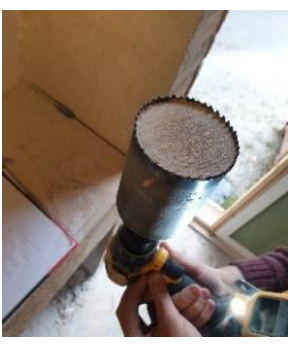

b)

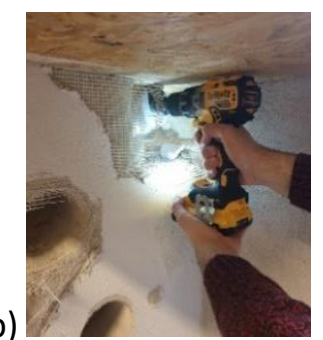

d)

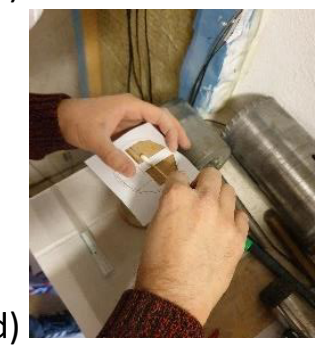

Fig. 2. Process of removing samples from the supportive wall plate. Measurements of moisture content (a) and Mycometer swabs (d) were performed on both ends of the samples.
Finally, two Mycometer swab tests [17-19] were made on each end of the drilled-out sample. Mycometer (surface) is a method for detection and quantification of mold growth on surfaces. The method is based on fluorometric detection and quantification of an enzyme found in mold spores and the mycelium. The Mycometer test generates a number that indicates the density of fungal biomass on the surface, corresponding to one of the following categories; A: $\leq 25$ (mold level is not above regular background level); B: 25-450 (mold level is above regular background level. This mold level can be caused by high concentrations in dust, or indicate the presence of dried-out mold), and; $\mathrm{C}$ : $>450$ (mold level is much higher than regular background level due to mold growth). The process of removing insulation, measuring moisture content, drilling the samples and Mycometer swabs, is illustrated in Fig. 2.

\section{Results and discussion}

The moisture content in the supportive wall plates over a 4-year time period of this study, are depicted in Fig. 3. An average between adsorption and desorption has been used under the assumption of equilibrium to surrounding air. It is seen, that the moisture content has an upper limit in this case, due to the limits of the sorption isotherm as was implemented [15], however the magnitude of the values are compatible with on-site measurements (see Fig. 7). It is seen, that after the first year of measurements, all the wall plates exhibit moisture contents between 20 and 33 $\%$ (wt.) for the entire period. Wall plates G4, X2 and X8 have few, shorter periods with moisture contents less than $20 \%$ (wt.). The conditions are thus above the threshold value for decay, and for this reason, these wall plates appear to be in high risk of occurrence of wood decaying fungi.

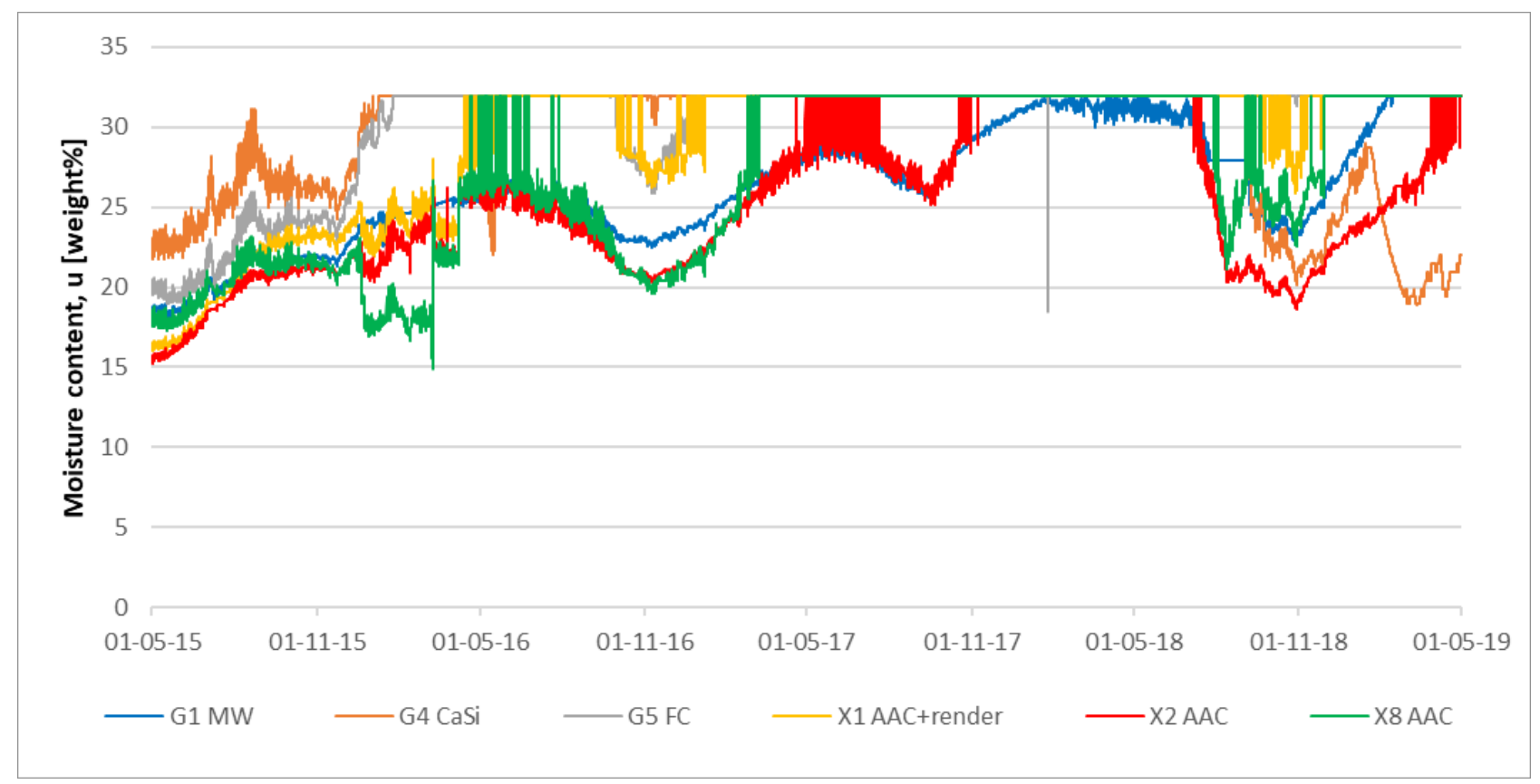

Fig. 3. Moisture content in the supportive wall plates, based on measurements of temperature and relative humidity, and sorption isotherms from pine [15] 
The monitored hygrothermal conditions for the six wall configurations presented in Table 2 were implemented in the wood decay models and the mold model respectively. The progression in values of wood decay and mold index over the 4 years of measurement data, are presented in Fig. 4, Fig. 5 and Fig. 6.

In the VTT model, three of the wall configurations (G4, G5 and X1) exhibit mass loss above $120 \%$ before 4 years. The remaining three wall configurations (X8, G1, X2) generated mass loss above $60 \%$ within 4 years. In terms of the Japanese model, the generated mass loss is less in terms of magnitude compared to the VTT model. The Japanese model yields mass loss above $60 \%$ in G4, G5 and X1. Wall X8 generated $40 \%$ mass loss in 4 years, whereas G1 and $\mathrm{X} 2$ resulted in around $20 \%$ mass loss. With regard to the value of the mold index, all the wall configurations show maximum value of mold index of 5.29 within 3 years. This is the maximum mold index value to be achieved for sensitivity class 2 . The worst cases $(\mathrm{G} 4, \mathrm{G} 5, \mathrm{X} 1)$ yielded the maximum value of mold index within the first year. Furthermore, it can be seen from the graphs of predicted wood decay and mold index (Fig. 4, Fig. 5, Fig. 6), that the initiation of mold growth occurs prior to the initiation of wood decay, which was also found to be the case in [11].

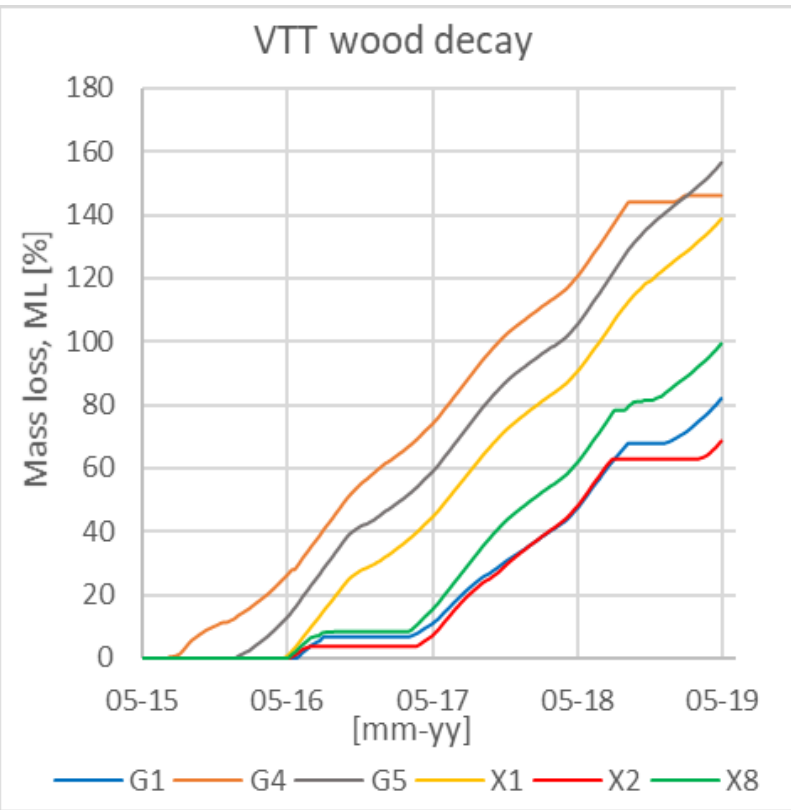

Fig. 4. Generated mass loss in the supportive wall plates for 6 wall configurations, with the VTT wood decay model, based on monitored temperature and relative humidity data

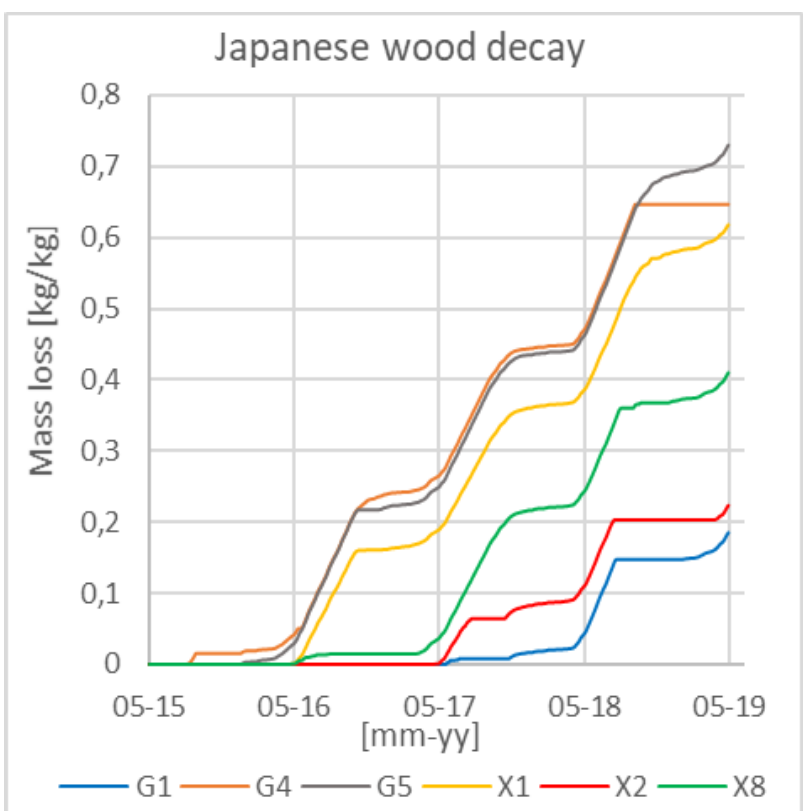

Fig. 5. Generated mass loss in the supportive wall plates for 6 wall configurations, with the Japanese wood decay model, based on monitored temperature and relative humidity data

The measurements of moisture content performed onsite, during the removal of samples from the wall plate, are presented in Fig. 7; this was performed in October 2019. The in-situ measurements reported in Fig. 3 are presented for up to $1^{\text {st }}$ of May 2019, and show a clear general tendency of nadirs in the autumn seasons.

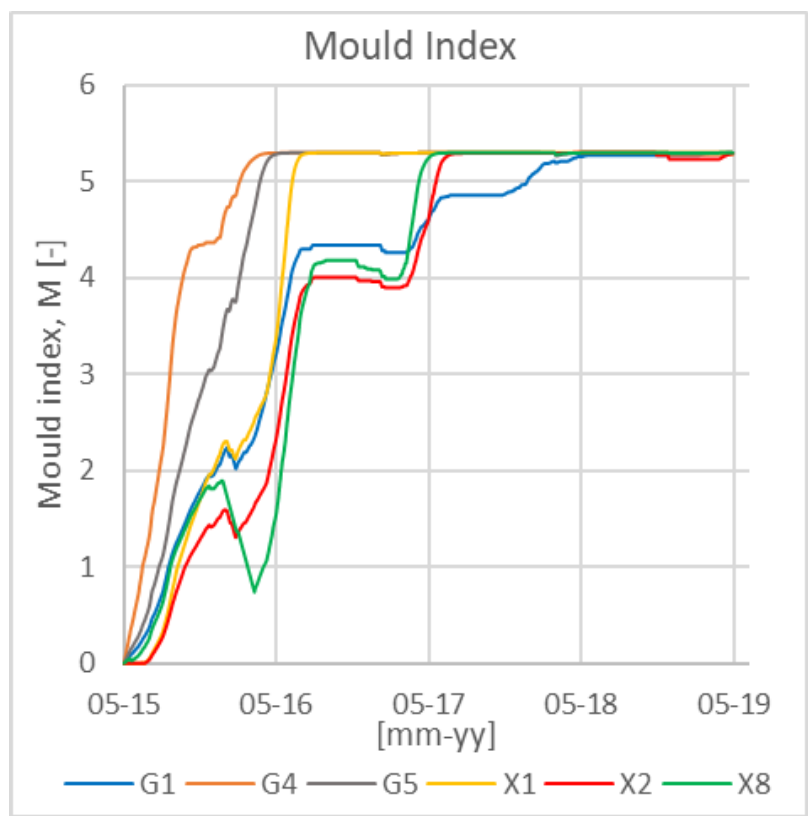

Fig. 6. Generated mold index in the supportive wall plates for 6 wall configurations, with the mold model, based on monitored temperature and relative humidity 


\section{Moisture content measurements}

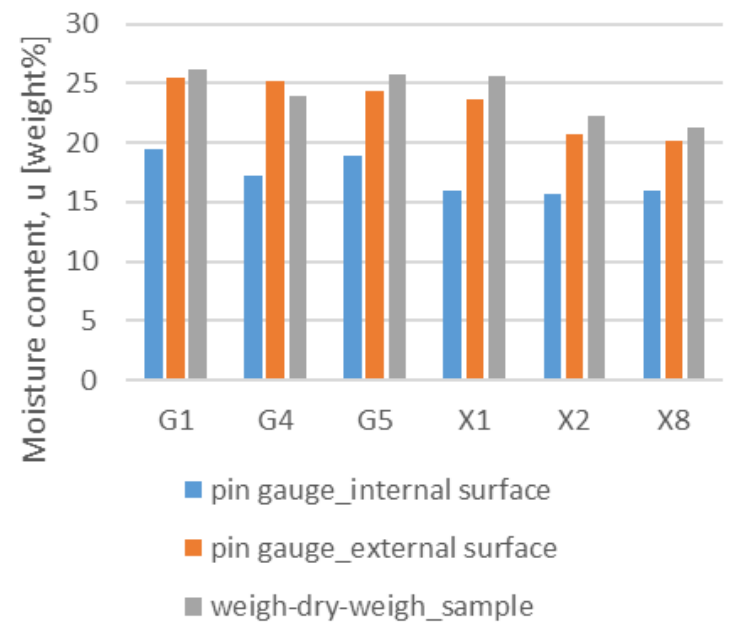

Fig. 7. Measurements of moisture content performed on site with pin gauge on internal and external surface, as well as the whole specimen

From the in-situ pin gauge measurements on the external surface of the sample, and the weigh-dry-weigh experiments on the samples, in Fig. 7 it is seen that the moisture content in the supportive wall plates is in the range of $20-27 \%$ (wt.). The moisture content on the internal surface is recorded as lower in all cases. This observation is in line with the expected results: Due to the temperature gradient, the relative humidity on the exterior side of the construction is higher and therefore also the moisture content. The effect from external moisture loads (e.g. wind-driven rain) may also influence the conditions on the external side of the wall plates, as the masonry covering the wall plate is only one brick unit in depth $(228 \mathrm{~mm})$. Furthermore, the anisotropic properties of wood promote moisture transport in the longitudinal direction and thus not tangentially through the wall plate. It is seen in Fig. 7, that samples from walls X2 and X8 yield the lowest moisture contents, consistent with Fig. 3. The measurements depicted in Fig. 3 also show, that G4 declined in moisture content by the spring of 2019 , however the measurements from October 2019 indicate that the moisture content has again increased. The procedure of drilling out the samples generated high temperatures, and this is why it can be assumed that the pin gauge measurements on the external surface, as well the weigh-dry-weigh measurements could be affected by this process. The moisture content registered on the external surface, as well as for the entire sample (weighdry-weigh), might therefore have been even higher without the generation of heat from drilling.

The state of the wooden core samples from the wall plates is seen in Fig. 8, as well as an example of the awl test. None of the wood samples exhibited any indication of mass loss nor rot or mold. Neither did the awl test, visual inspection or smelling indicate anything other than sound and healthy wood. The discolorations seen in the wood samples, were due to the drilling procedure, and from the wall construction and adjacent materials.

Results from Mycometer (surface) measurements are displayed in Table 3. None of the Mycometer measurements exhibit results in category $C$, above 450 , which would be a clear indication of severe mold growth. The calculations with the mold model were performed with measurements from the external surface of the wall plate. The mold model yielded high mold index for all the cases, but G4, G5 and X1 generated mold growth the fastest. Two of these, G5 and X1 show the lowest density of mold with regard to the Mycometer tests on the external surface. The highest mold density was found on the external surface of $\mathrm{X} 2$, which in the model was shown to be almost the last case to reach the maximum value of mold index.

Table 3. Results from Mycometer (surface) tests. Green color represents result values within category A, while yellow color represents values within category $\mathrm{B}$. None of the swabs generated results within category $\mathrm{C}$.

\begin{tabular}{|r|r|r|r|r|}
\hline & \multicolumn{2}{|c|}{ Internal surface } & \multicolumn{2}{c|}{ External surface } \\
\cline { 2 - 5 } & swab 1 & swab 2 & \multicolumn{1}{c|}{ swab 1 } & \multicolumn{1}{c|}{ swab 2 } \\
\hline G1 & 129 & 159 & 44 & 42 \\
\hline G4 & 21 & 12 & 51 & 117 \\
\hline G5 & 29 & 30 & 20 & 24 \\
\hline X1 & 72 & 72 & 14 & 22 \\
\hline X2 & 15 & 26 & 106 & 299 \\
\hline X8 & 41 & 18 & 60 & 35 \\
\hline
\end{tabular}

Thus, it is seen, that prediction models for wood decay and mold growth, in this case, appear too conservative with regard to the actual state of the rot and mold, as the degree of deterioration and mold as the results obtained from the model appear to be exaggerated. The VTT wood decay model predicted $60-160 \%$ mass loss in all the cases, where no rot or decay was actually detected. The Japanese decay model appears to be less conservative, however the model generated mass loss above $20 \%$ for all cases, while no mass loss was observed. The difference between the two models is first and foremost the threshold value for rot; the VTT model initiates decay at $95 \%$ relative humidity,
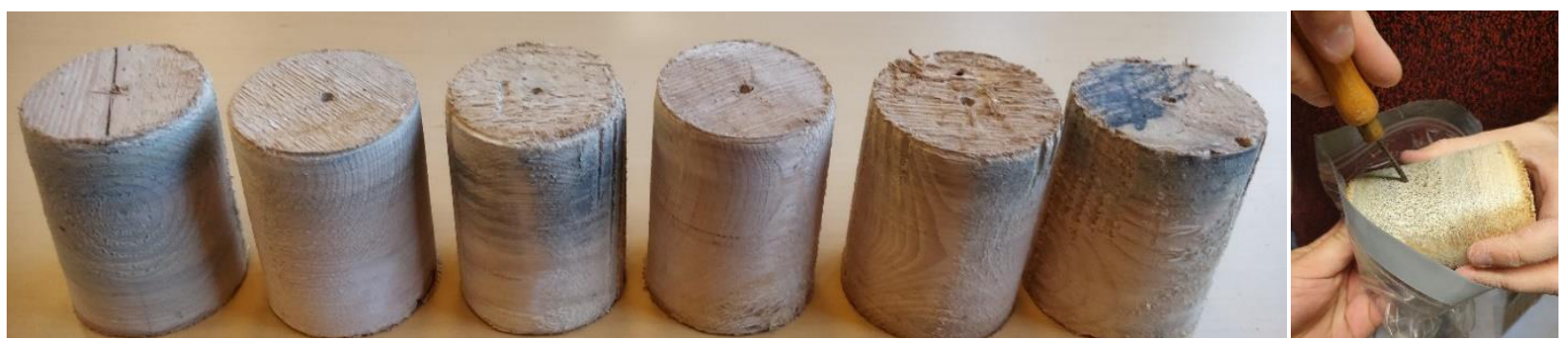

Fig. 8. Left: The 6 specimens drilled out from the supportive wall plates from the 6 wall configurations; left to right: X1, X2, X8, G1, G4, G5. Right: awl test of a specimen. 
whereas the Japanese threshold for wood decay is $98 \%$ relative humidity. In addition, the mold model generated alarmingly high mold index in all the cases, corresponding to "plenty of growth on surface, $>50 \%$ coverage (visual)", whilst no significant mold growth was detected by the Mycometer surface experiments nor visual inspection.

With regard to the six investigated samples, the hygrothermal performance can be ranked in the following sequence according to monitored conditions, see Fig. 3; $\mathrm{X} 2, \mathrm{G} 1, \mathrm{X} 8, \mathrm{X} 1, \mathrm{G} 4$, and G5. The wood decay models yield very similar results with regard to the performance and mass loss achieved, which is not surprising as these prediction models are based on the hygrothermal conditions provided. The mold model gave a mold index value above 5 for all the wall plates investigated, which were differentiated only by the time it took to reach the maximum value of mold index.

The summation of Mycometer results on each wall plate, however, yielded a different sequence of optimal performance; G5, X8, X1, G4, G1, X2. The highest Mycometer numbers, were thus found in X2 (external side) and G1 (internal side), despite the fact that these wall plates exhibited the lowest moisture contents during in-situ measurements (Fig. 3), and as such, from the prediction results were the last to reach the maximum value of mold index. Thus, the Mycometer results were not consistent with the moisture content determinations and the predicted risks of neither wood decay nor mold growth. G1 yielded the highest Mycometer number on the internal surface, which may be partly explained by the fact that this insulation system is the only one represented without alkaline cementitious glue mortar, that can inhibit mold growth [20]. Furthermore, the quality, sawing and finishing of the wood may differ from wall to wall, which may also affect the results.

It should be noted, that the physical methods applied for detection of mould and/or decay (visual, odor, awl, mycometer) are indicative methods. This fact naturally reduces the reliability of the results, and may be cause of some discrepancies. However, the combined indicators all yield similar results. The moisture conditions in the supportive lath yield very high moisture content, and the uncertainty in the monitoring equipment is only given for up to $90 \% \mathrm{RH}$. Therefore, the in-situ measurements themselves also carry uncertainties, that are included in the prediction models.

Furthermore, some of the discrepancies can be explained by the fact that the mold model was developed for surface conditions, not built-in surfaces, for worst case (untreated pine sapwood) and based on small specimens with mainly constant climate conditions [11]. The updated mold model implemented in this study does allow better prediction by including the sensitivity classification, and mold condition states to yield reliable predictions of first biological growth at interfaces [10], however the results still appear too conservative. Some of the reasons provided for these discrepancies also apply to the VTT wood decay models, given that these were based on experiments under constant hygrothermal conditions for small samples of untreated pine sapwood [5], and on small samples of Japanese red pine for the Japanese model [8]. Despite the discrepancies found in this study, the models provide indications of potential risks of fungal attacks under the given hygrothermal conditions and exposure time. In this way, the models can be used to evaluate systems a comparative basis and in relation to one another, and thus, permit establishing better or poorer performance. Such results, however, could also be achieved by observation of the measured moisture contents alone.

\section{Conclusions}

From the present investigation it was found that:

- The wood decay models were too conservative in this case. The VTT model yielded $60-160 \%$ mass loss, and the Japanese model gave $20-70 \%$ mass loss in the wall plates, and none was detected by visual inspection and awl compression test.

- The mold model was too conservative as all the samples from the wall plates yielded predicted mold index values above 5, but no significant mold growth was detected on the samples by visual inspection nor Mycometer measurements.

- The presented models all appear to overestimate the potential risks of wood decay and mold growth respectively. The models can be used for comparison purposes of different solutions under given conditions. This may however also be evaluated from a review of results of moisture content alone. The models should be further developed to be applicable for evaluation of moisture safe construction assemblies.

- Mold growth is initiated prior to wood decay based on the same parameters of temperature, relative humidity and time; as such, mold (in most cases) could be a limiting factor with regard to "moisture safe" solutions in critical positions where the presence of mold is not acceptable.

- In cases where mold growth is not a threat for indoor air quality, e.g., built-in wood in constructions that do not have air transfer to indoors, wood decay would be the relevant failure mode.

- The initiation of mold growth in building construction always indicates the presence of excess moisture, which is an undesirable condition and likely caused by a building defect or certainly an issue that should be addressed.

Acknowledgements to GI (Grundejernes Investeringsfond) and EU's Horizon 2020 research and innovation programme under grant agreement no. 637268 (RIBuild). 


\section{References}

1. J. Singh, Indoor Built Environ. 8 3-20 (1999)

2. Teknologisk Institut, https://www.trae.dk/leksikon/nedbrydning-aftrae/ (2019).

3 A.P. Koch, H.J. Larsen, O. Munck, BYG-ERFA, 031219 (2003)

4. A.P. Koch, O. Munck, H.J. Larsen, BYG-ERFA, 031228 (2003)

5. H. Viitanen, T. Toratti, L. Makkonen, R. Peuhkuri, T. Ojanen, L. Ruokolainen, J. Räisänen, Eur. J. Wood Wood Prod. 68 303-313 (2010)

6. $\quad$ S.F. Curling, C.A. Clausen, J.E. Winandy, Int. Biodeterior. Biodegrad. 49 13-19 (2002)

7. C. Brischke, L. Meyer-Veltrup, Mater. Struct. 49 3281-3291 (2016)

8. H. Saito, K. Fukuda, T. Sawachi, Build. Therm. Light. Acoust. Model. 5 315-324 (2012)

9. H. Saito, 11th Nord. Symp. Build. Physics, NSB2017, 399-404 (2017)

10. T. Ojanen, R. Peuhkuri, H. Viitanen, K. Lähdesmäki, J. Vinha, K. Salminen, 9th Nord. Symp. Build. Phys. NSB2011, 867-874 (2011)

11. A. Hukka, H. Viitanen, Wood Sci. Technol. 33 475-485 (1999)

12. T. Odgaard, S.P. Bjarløv, C. Rode, Energy Build. 173 530-546 (2018)

13. N.F. Jensen, S.P. Bjarløv, C. Rode, T.R. Odgaard, Ce Pap. 2 79-87 (2018)

14. N. Feldt Jensen, S.P. Bjarløv, DTU Civ. Eng. https://backend.orbit.dtu.dk/ws/portalfiles/portal/ 187292747/Rapport_fra_DTU_om_indvendig_ef terisolering.pdf (2019)

15. K. Kielsgaard Hansen, DTU Civ. Eng. Report no. TR-162, http://docplayer.net/5813927Sorption-isotherm-s-a-catalogu-e-kurtkielsgaard-hanse-n.html (1986)

16. L.L. Andersen, C. Kjerumgaard, Videnscentret Bolius. https://www.bolius.dk/tjek-vinduerhavedoere-og-yderdoere-af-trae-18319 (2016)

17. Mycometer, http://cdn.mycometer.com/fileadmin/user_uploa d/Pdf/Mycometer-Surface_Flyer_2012_.pdf (2012)

18. M. Reeslev, M. Miller, Proc. Heal. Build. 589590 (2000)

19. M. Miller, A. Palojärvi, A. Rangger, M. Reeslev, A. Kjøller, Appl. Environ. Microbiol. 64 613617 (1998)

20. H. Viitanen, M. Krus, T. Ojanen, V. Eitner, D. Zirkelbach, Energy Procedia. 78 1425-1430, 6th International Building Physics Conference, IMPC2015 (2015) 